\title{
Can we Really Have an Integrative Theory of Creativity? The Case of Creative Cognition
}

\author{
Roni Reiter-Palmon \\ Department of Psychology, University of Nebraska Omaha, USA \\ E-mail: rreiter-palmon@unomaha.edu
}

\section{ARTICLE INFO}

\section{Keywords:}

Creative cognition

Problem identification

Idea evaluation

Article history:

Received 28 October 2014

Received in revised form 19 December 2014

Accepted 20 December 2014

ISSN: 2354-0036

DOI: 10.15290/ctra.2014.01.02.13

\section{A B STRACT}

In this commentary to Glăveanu (2014), I address one specific issue raised - that of the need for a grand or unifying theory of creativity. I discuss whether our understanding of creative cognition has progressed sufficiently to allow for the development of, or inclusion in, a grand theory of creativity. Specifically, I argue that there are many gaps in our understanding of two major processes, problem identification and construction and idea evaluation and choice. I further provide some suggestions for how we can move the field forward on these individual aspects, and still strive for integration.

In his paper, Glăveanu (2014) provides an overview of the field and research in creativity, and suggests that we must move toward a more integrative approach. I do not disagree. Indeed, at times, it does feel that we are doing fairly narrow work, and that we forget to consider how all the various findings tie together, and how they fit with a larger theoretical framework. As research in the area of creativity has expanded, and exploded, in recent years, keeping track of these disparate findings, and making sense of sometimes conflicting findings has become more difficult.

That said, I believe that there are still some areas in which we have a significant lack of knowledge, and proceeding to a unifying approach, a grand theory, without the basic knowledge can be problematic. One example of an area where we have a much more limited understanding is that of the cognitive processes associated with creative thinking. While many theories of cognition have been proposed (Finke, Ward, \& Smith; 1992; Merrifield, Guilford, Christensen, \& Frick; 1962; Mumford, Mobley, Uhlman, Reiter-Palmon, \& Doares, 1991; Osborn, 1953; Sternberg, 1988; Wallace, 1926), testing of all the specific processes proposed has lagged behind. Reiter-Palmon and Illies (2004) suggested that there are some common processes across the different models such as problem identification and construction, idea generation and idea evaluation and selection. When looking 
at these three processes, it is clear that idea generation has been extensively evaluated. In fact, in some cases, idea generation has become the de-facto measure and definition of creativity (Reiter-Palmon, Herman, \& Yammarino, 2008).

While research on idea generation has been plentiful, that is less so the case with the other two processes. As a result, what we know about these two important processes is limited. In the case of problem identification and construction, we know that creative individuals tend to engage in the process and be better at it, than less creative individuals (Getzels \& Csikszentmihalyi, 1975; Okuda, Runco, \& Berger, 1991; Reiter-Palmon, Mumford, \& Threlfall, 1998), that experts spend more time in problem construction than novices (Kay, 1991; Rostan, 1994; Voss, Wolfe, Lawrence, \& Engle, 1991) and that when individuals are asked to actively engage in the process, they are more likely to come up with creative ideas (Redmond, Mumford, \& Teach, 1993; Reiter-Palmon, Mumford, O'Connor Boes, \& Runco, 1997). With regard to idea evaluation and choice, we know that individuals can accurately evaluate ideas for originality (Runco \& Basadur, 1993; Runco \& Chand, 1995). That said, other work suggests that more creative individuals are more accurate in their evaluations (Basadur, Runco, \& Vega, 2000). While idea evaluation was found to be related to divergent thought more so than convergent thought (Runco \& Smith, 1992), factors that influence idea generation seem to influence idea evaluation in a different way (Herman \& Reiter-Palmon, 2011). Finally, the standards that influence idea evaluation are different based on domain (Sullivan \& Ford, 2005)

However, there is still much we do not know about these two processes. For example, multiple methods have been used to elicit active engagement problem identification and construction (Reiter-Palmon \& Robinson, 2009) though it is not clear whether and how these methods may differ in terms of their effect on the process of problem identification and construction and resulting creativity. In addition, it has been suggested that problem identification and construction is related to experience (Gick \& Holyoak, 1983), and research indeed suggests that experts spend more time constructing an ill-defined problem, however, the exact nature of the role of experience in how the problem is constructed has not been examined. For idea evaluation, the relationship between idea evaluation and idea choice has not been fully examined. For both problem identification and construction and idea evaluation, the differences between the processes at the individual and team level have not been examined. It is not clear if these processes operate in the same way at the team level, or in what way are individual cognitions aggregated or combined to create a team problem construction or team evaluation (Reiter-Palmon, Wigert, \& de Vreede, 2011).

While understanding how these processes operate and the basic factors that influence them is important, following the call by Glăveanu, I would like to suggest some additional 
important issues that require a broader and integrative perspective to study. That said, given the limited basic research, I do not believe this particular area is yet ripe for a grand integrative theory. Instead, I would suggest that in addition to studying and understanding each process in isolation, we are indeed ready for the next step - integrating these processes with other factors that influence creativity. One area in which we need to focus on integration is within the study of the processes themselves. Investigations into how the specific processes interact with one another and affect one another are limited. For example, how does structuring the results from problem identification and construction influence the information that is being searched? How do the goals developed in the problem construction phase influence the standards used to evaluate solutions? How do the number and creativity of the ideas generated influence idea evaluation and selection? Further, while it has been suggested that these processes may not necessarily occur in a sequential manner (Mumford et al., 1991), and that individuals may cycle back and forth between the processes, how and when this is done is not well understood.

Other important integrative research questions have to do with the potential influences of other factors such as personality, motivation, social processes, leadership and culture (at both the organization and national level) on the application of these processes. For example, research suggests that problem construction effectiveness is related to personality (Reiter-Palmon, Mumford, \& Threlfall, 1998) and that promotion and prevention foci, a motivational characteristic, have different and opposite relationships with idea generation and idea evaluation (Herman \& Reiter-Palmon, 2011). The role of additional personality and motivational characteristics such as goal orientation, emotional stability, creative self-efficacy, task interest and intrinsic motivation should be further investigated. Further, it is important to delineate the effects of these variables on the different processes independently and interactively. Similarly, it is not clear how culture (be it departmental, organizational or national) or social processes (such as communication, cohesion or conflict) will influence creative cognitive processes. For example, do cultures that emphasize risk taking promote idea evaluation and selection of more risky, and potentially more original, ideas? Do open discussions within teams facilitate sharing different perspective about the problem, and the development of broader and more comprehensive problem identification and construction?

Glăveanu (2014) suggests that it is important that we move from disjointed individual findings to a more coherent state of affairs in the study of creativity. I agree that the field is ready, to some extent, to move beyond single findings into studying more complex relationships. I have reviewed the state of research on early and late cognitive processes, those that precede idea generation and those that come after. While I agree that we must 
strive for a more unifying approach to the study of creativity, the research has not progressed in a uniform fashion across the different areas of creativity. Creative cognition is one aspect where progress has been slow, at least in some areas, and therefore, we may not be able to develop a global approach.

\section{REFERENCES}

Basadur, M.S., Runco, M.A., \& Vega, L.A. (2000). Understanding how creative thinking skills, attitudes, and behaviors work together: A causal process model. Journal of Creative Behavior, 34, 77-100.

Finke, R.A., Ward, T.B., \& Smith, S.M. (1992). Creative cognition: Theory, research, and applications. Cambridge, MA: MIT Press.

Ford, C. \& Sullivan, D.M. (2005). A time for everything: How the timing of novel contributions influences project team outcomes. Journal of Organizational Behavior, 25, 279-292.

Getzels, J.W. \& Csikszentmihalyi, M. (1975). From problem solving to problem finding. In I.A. Taylor \& J.W. Getzels (Eds.), Perspectives in creativity (pp. 90-116). Chicago, IL: Aldine.

Gick, M.L. \& Holyoak, K.J. (1983). Schema induction and analogical transfer. Cognitive Psychology, 15, 1-38.

Glăveanu, V.P. (2014). The psychology of creativity: A critical reading. Creativity. Theories - Research - Applications, 1, p. 10-32, DOI: 10.15290/ctra.2014.01.01.02.

Herman, A. \& Reiter-Palmon, R. (2011). The effect of regulatory focus on idea generation and idea evaluation. Psychology of Aesthetics, Creativity, and the Arts, 5, 13-21.

Kay, S. (1991). The figural problem solving and problem finding of professional and semiprofessional artists and nonartists. Creativity Research Journal, 13, 185-195.

Merrifield, P.R., Guilford, J.P., Christensen, P.R., \& Frick, J.W. (1962). The role of intellectual factors in problem solving. Psychological Monographs, 76, 1-21.

Mumford, M.D., Mobley, M.I., Uhlman, C.E., Reiter-Palmon, R., \& Doares, L.M. (1991). Process analytic models of creative capacities. Creativity Research Journal, 4, 91-122.

Okuda, S.M., Runco, M.A., \& Berger, D.E. (1991). Creativity and the finding and solving of real-world problems. Journal of Psychoeducational Assessment, 9, 45-53.

Osborn, A.F. (1953). Applied imagination: Principles and procedures for creative problem -solving. New York, NY: Charles Scribner \& Sons.

Redmond, M.R., Mumford, M.D., \& Teach, R. (1993). Putting creativity to work: Effects of leader behavior on subordinate creativity. Organizational Behavior and Human Decision Processes, 55, 120-151.

Reiter-Palmon, R. \& Illies, J.J. (2004). Leadership and creativity: Understanding leadership from a creative problem-solving perspective. Leadership Quarterly, 15, 55-77. 
Reiter-Palmon, R., Herman, A.E., \& Yammarino, F. (2008). Creativity and cognitive processes: A multi-level linkage between individual and team cognition. In Mumford, M.D., Hunter, S.T., \& Bedell-Avers, K.E. (Eds.), Multi - level Issues in Creativity and Innovation, (vol. 7, pp. 203-267). Greenwich, CT: JAI Press.

Reiter-Palmon, R., Mumford, M.D., O'Connor Boes, J., \& Runco, M.A. (1997). Problem construction and creativity: The role of ability, cue consistency, and active processing. Creativity Research Journal, 10, 9-23.

Reiter-Palmon, R., Mumford, M.D., \& Threlfall, K.V. (1998). Solving everyday problems creatively: The role of problem construction and personality type. Creativity Research Journal, 11, 187-197.

Reiter-Palmon, R. \& Robinson, E.J. (2009). Problem identification and construction: What do we know, what is the future? The Psychology of Aesthetics, Creativity, and the Arts, 3, 43-47.

Reiter-Palmon, R., Wigert, B., \& de Vreede, T. (2011). Team creativity and innovation: The effect of team composition, social processes and cognition. Handbook of Organizational Creativity (pp. 295-326). San Diego, CA: Academic Press.

Rostan, S.M. (1994). Problem finding, problem solving, and cognitive controls: An empirical investigation of critically acclaimed productivity. Creativity Research Journal, 7, 97-110.

Runco, M.A. \& Basadur, M.S. (1993). Assessing ideational and evaluative skills and creative styles and attitudes. Creativity and Innovation Management, 2, 166-173.

Runco, M.A. \& Chand, I. (1995). Cognition and creativity. Educational Psychology Review, 7, 243-268.

Runco, M.A. \& Smith, W.R. (1992). Interpersonal and intrapersonal evaluations of creative ideas. Personality and Individual Differences, 13, 295-302.

Sternberg, R.J. (1988). A three-facet model of creativity. In R.J. Sternberg (Ed.), The nature of creativity: Contemporary psychological perspectives (pp. 125-147). New York: Cambridge University Press.

Voss, J.F., Wolfe, C.R., Lawrence, J.A. \& Engle, R.A. (1991). From representation to decision: An analysis of problem solving in international relations. In R.J. Sternberg \& P.S. Frensch (Eds.), Complex problem solving: Principles and mechanisms (pp. 119158). Hillsdale, NJ: Erlbaum.

Wallas, G. (1926). The Art of Thought. New York: Harcourt Brace.

Ward, T.B., Smith, S.M., \& Finke, R.A. (1999). Creative cognition. In R.J. Sternberg (Ed.), Handbook of creativity (pp.189-212). New York: Cambridge University Press.

Corresponding author at: Roni Reiter-Palmon, Department of Psychology, University of Nebraska at Omaha, 6001 Dodge Street, Omaha, NE 38182-0274, USA.

E-mail: rreiter-palmon@unomaha.edu 